\title{
Sound Absorption Coefficient of Glass Wool
}

\author{
By Sadao Aso and Rikuhiro Kinoshita, Members, TMSJ \\ Faculty of Engineering, Tokyo University of Agriculture \\ and Technology, Koganei, Tokyo.
}

Based on the Journal of the Textile Machinery Society of Japan, Transactions, Vol. 18, No. 11, T 649-653 (1965)

\begin{abstract}
This article presents the results of an investigation into the relation between the normal incident sound absorption coefficient and the apparent density of glass wool boards used as a sound absorbent.

(1) Only one kind of glass wool boards $64 \mathrm{~kg} / \mathrm{m}^{3}$ in apparent density and $2.5 \mathrm{~cm}$ in thickness out of 20 kinds made by 3 manufacturers has given a sound absorption characteristic belonging to the mixed type. The sound absorption characteristics of the other kinds of glass wool boards have been shown by experiment to belong to the viscosity-resistance type.

(2) The relation between effective apparent density Dea $\left(\mathrm{kg} / \mathrm{m}^{3}\right)$ at which a glass wool board gives 1.00 in sound absorption coefficient and the thickness $T(\mathrm{~cm})$ is :$$
D_{e a}=a T^{-b}
$$

where $a$ and $b$ are constants fixed by the manufacturer.

(3) The relation among apparent density $D a\left(\mathrm{~kg} / \mathrm{m}^{3}\right)$, thickness $T(\mathrm{~cm})$, distance $d(\mathrm{~cm})$ between the center of a sample and the rigid wall, and frequency $f_{0}$ at which the sample gives the maximum sound absorption coefficient is expressed by the following empirical formula :

$$
f_{0}=\left(c / 4-\alpha D^{3} \cdot T\right) d^{-1}
$$

where $\alpha$ and $\beta$ are constants and $c$ is the speed of sound.
\end{abstract}

\section{Introduction}

Previous articles reported on the influence which several factors in the make-up of a fiber assembly have on sound absorption characteristics $[1]$; the relationship between the maximum absorption coefficient and those factors; and the effective porosity of sound. absorbing fibrous materials[2]. The present article deals with the relation between the sound absorption characteristics and the apparent density of commercially sold glass wool boards which are representative of many kinds of sound-absorbing fibrous materials.

\section{Method of Experimenting}

There are the reverberation room method and the tube method to measure the sound absorption coefficient of materials. We measured the normal incident sound absorption coefficient (abbreviated here to "sound absorption coefficient") by the tube method. The theory and apparatus for measuring sound absorption coefficient are the same as those we used to measure the sound absorption coefficient of fabrics[3]. Sound absorption coefficients were measured from 250 $\mathrm{c} / \mathrm{s}$ to $2000 \mathrm{c} / \mathrm{s}$ at intervals of $1 / 3$ octaves generally. Where necessary, we also made measurements with frequencies in between.

We used, as samples, 20 kinds of glass wool boards, $61 \mathrm{~cm}$ by $91.5 \mathrm{~cm}$ in size, made by three manufacturers in Japan. Their nominal thickness and apparent density are given in Table 1 . Many specimens, $10 \mathrm{~cm}$ in diameter, were cut out of the glass wool boards, with a circular punch installed in a drill press. The apparent density of the specimens fluctuated, making an observed apparent density generally different from the nominal apparent density of the glass wool board.

Five or six specimens were picked out of many belonging to one kind of glass wool board in such a 
Table 1 Dimension of Glass Wool Boards Measured and Manufacturers

\begin{tabular}{|c|c|c|c|}
\hline $\begin{array}{l}\text { Nominal } \\
\text { thickness } \\
\quad(\mathrm{cm})\end{array}$ & $\begin{array}{l}\text { Nominal } \\
\text { apparent } \\
\text { density } \\
\left(\mathrm{kg} / \mathrm{m}^{3}\right)\end{array}$ & $\begin{array}{l}\text { Manu- } \\
\text { facturer }\end{array}$ & $\begin{array}{l}\text { sample Nos. } \\
\text { (NO.) }\end{array}$ \\
\hline \multirow{3}{*}{1.3} & 8 & A \& Co. & 1 \\
\hline & 12 & A \& Co. & 2 \\
\hline & 24 & A \& Co. & 3 \\
\hline \multirow{9}{*}{2.5} & 8 & A \& Co. & 4 \\
\hline & 10 & C \& Co. & 5 \\
\hline & \multirow{2}{*}{12} & A \& Co. & 6 \\
\hline & & B \& Co. & 7 \\
\hline & 20 & C \& Co. & 8 \\
\hline & \multirow{2}{*}{24} & A \& Co. & 9 \\
\hline & & B \& Co. & 10 \\
\hline & 32 & B \& Co. & 11 \\
\hline & 64 & B \& Co. & 12 \\
\hline \multirow{8}{*}{5.0} & 8 & A \& Co. & 13 \\
\hline & 10 & C \& Co. & 14 \\
\hline & \multirow{2}{*}{12} & A \& Co. & 15 \\
\hline & & B \& Co. & 16 \\
\hline & 20 & C \& Co. & 17 \\
\hline & \multirow{2}{*}{24} & A \& Co. & 18 \\
\hline & & B \& Co. & 19 \\
\hline & 32 & B \& Co. & 20 \\
\hline
\end{tabular}

way they would differ in apparent density from one another at about regular intervals. Each specimen picked out was inlaid into a ring having the same thickness as the specimen, and was then put in a measuring tube in such a way that it had an air space behind it. The idea of the air space behind the specimens was to obtain, within the limits of measured frequencies, the maximum sound absorption coefficient of a specimen small in apparent density or of a specimen small in thickness.

\section{Types of Absorption Characteristics}

A previous article[2] classified the types of absorption characteristics of fiber assemblies into 4 : the viscosity resistance type, the mixed type, the fibrous resonance type and the board resonance type. The article made it clear that the absorption characteristics of fiber assemblies changed from the viscosity resistance type to, successively, the mixed type and the resonance type as they decreased in porosity.

Fig. 1 shows the absorption characteristics of glass wool boards differing in apparent density (Da), namely,

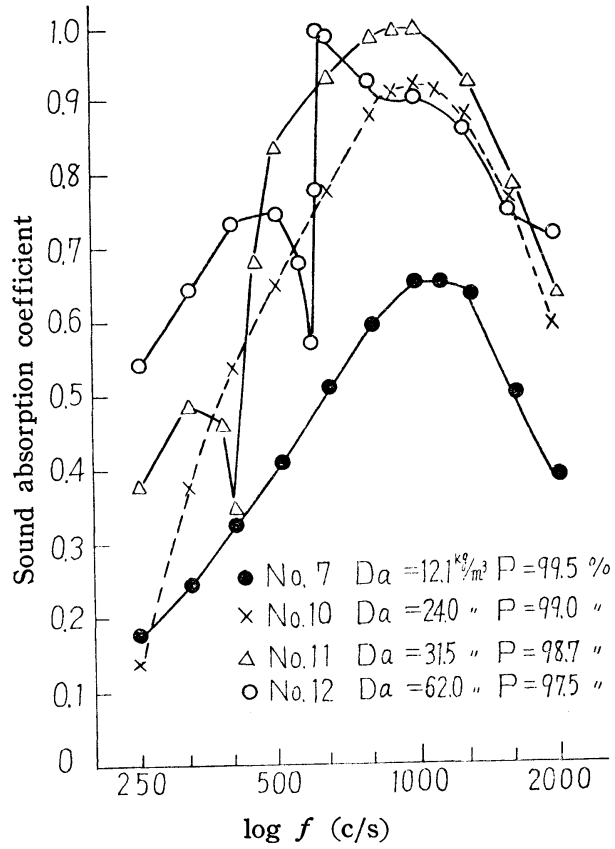

Fig. 1 Sound absorption characteristics of glass wool boards $2.5 \mathrm{~cm}$ thick

$D_{a}$ : Observed apparent density

$P$ : Porosity

porosity $(\mathrm{P})$. Porosity was calculated with the specific gravity of a glass fiber as 2.49. Samples Nos. 7 and 8 belong to the viscosity resistance type.

Although sample No. 11 should have been classified as of the mixed type in its absorption characteristics, we treated it as of the viscosity resistance type, because sound absorption belonging to the viscosity resistance type was predominant in its characteristic and because the maximum absorption coefficient at about $900 \mathrm{c} / \mathrm{s}$ acquires the properties of sound absorption attributed to the mechanism of the viscosity resistance type.

Sample No. 12 is a typical mixed type. The larger a sample is in thickness, the more readily its absorption characteristic changes from the viscosity resistance type to the mixed type at a high porosity degree. However, sample No. 12 excepted, we were able to treat all samples, even those $5 \mathrm{~cm}$ thick, as of the viscosity resistance type.

\section{Maximum Absorption Coefficient and Apparent Density}

The absorption characteristics of the specimens of all kinds of glass wool boards were obtained by keeping 
the distance between the front surface af a specimen and the rigid wall in the measuring tube at $8.5 \mathrm{~cm}$. Accordingly, the air space behind a specimen differed in depth as the glass wool boards differed in thickness.

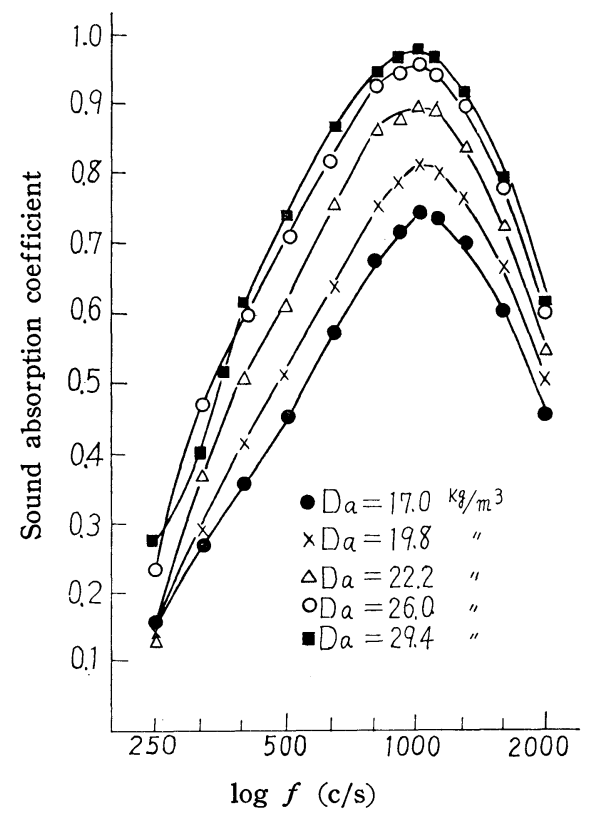

Fig. 2 Sound absorption characteristics of specimens belonging to sample No. 10

$D_{a}$ : observed apparent density

One example is Fig. 2 which gives the absorption characteristics of 5 specimens belonging to No. 11 and the characteristics of the remainder were shown in Fig. 1. The figures illustrate that sound absorption coefficient increases as apparent density increases; and that the maximum absorption coefficient is influenced extremely by apparent density. The order of apparent density in No. 11 coincided with the maximum absorption coefficient, but this was not the case with every sample. Even a specimen having a large value in apparent density is small in sound absorption coefficient if it has a big space in it or if its air channel runs straight from the front surface to the back surface of the specimen.

Fig. 3 shows the relationship between the maximum absorption coefficient and apparent density for 9 kinds of glass wool boards manufactured by A \& Co. If they are uniform in thickness, their maximum absorp. tion coefficient increases with an increase in their apparent density and reaches 1.00 at a certain value of apparent density. We call this apparent density "effective apparent density Dea of the glass wool board." The values of Dea for the glass wool boards made by the 3 manufacturing firms are given in Table 2. The values for the glass wool boards manufactured by $\mathrm{C} \&$ Co. are the smallest of all. This shows clearly that $\mathrm{C} \& \mathrm{Co}$. 's products are made of the finest of glass fibers used by the 3 firms.

Table 2 Effective Apparent Density Dea $\left(\mathrm{kg} / \mathrm{m}^{3}\right)$

\begin{tabular}{cccc}
\hline & & & \\
Manufacturer & 1.3 & 2.5 & 5.0 \\
\hline A \& Co. & $39 \sim 40$ & $25 \sim 26$ & $16.5 \sim 17.5$ \\
B \& Co. & - & $34 \sim 35$ & $27 \sim 29$ \\
C \& Co. & - & $17 \sim 19$ & $14.5 \sim 15.5$ \\
\hline
\end{tabular}

Table 3 Constants $a$ and $b$ in Empirical Formula $D_{e a}=a T^{-b}$ $D_{e a}:$ Effective apparent density $\left(\mathrm{kg} / \mathrm{m}^{3}\right)$ $T:$ Thickness $(\mathrm{cm})$

\begin{tabular}{rcc}
\hline constant & $a$ & $b$ \\
\hline Manufacturers & & 0.635 \\
A \& Co. & 46.5 & 0.300 \\
C \& Co. & 45.4 & 0.263 \\
\hline
\end{tabular}

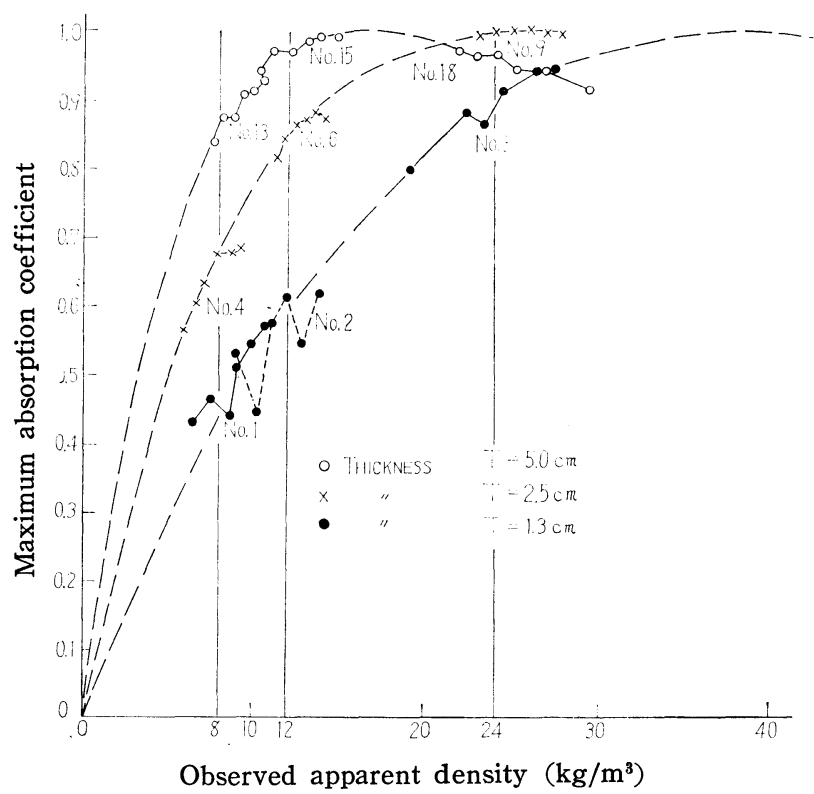

Fig. 3 Bearing of thickness on relation between maximum absorption coefficient and observed apparent density of glass wool boards manufactured by $\mathrm{A} \&$ Co. 


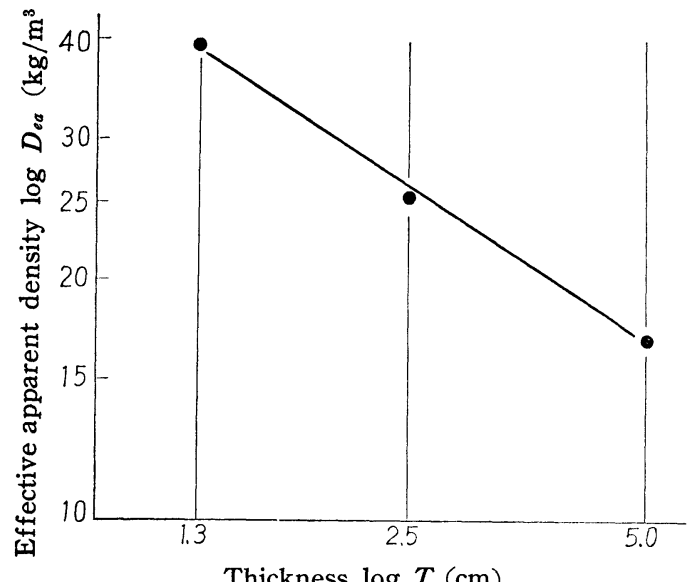

Fig. 4 Relation between effective apparent density $D_{e a}$ and thickness of the glass wool boards manufactured by A \& Co.

The relation between Dea and thickness $T$ of samples made by A \& Co. is, as shown in Fig. 4, a line on log-log section paper. Accordingly, this relation is given by the following formula:

$$
\text { Dea }=a T^{-b}
$$

where $a$ and $b$ are constants.

A fiber assembly has an effective porosity $\mathrm{Pe}(\%)$, at which the maximum absorption coefficient reaches 1.00, and the relation between $P e$ and $T$ is :

$$
(100-P e)=a^{\prime} T^{-b^{\prime}}
$$

where $a^{\prime}$ and $b^{\prime}$ are constants.[2]

It seems, therefore, that eq. (1) holds good for the glass wool boards made by B \& Co. and C \& Co., although measured samples were only 2.5 or $5.0 \mathrm{~cm}$ thick.

Constants $a$ and $b$ in eq. (1) calculated from measured results are given in Table 3. The Dea for a glass wool board having an optional thickness is calculable from eq. (1). Each manufacturer sells glass wool boards of the same nominal apparent density but of different thicknesses. However, they can be reduced in apparent density by increasing their thickness.

\section{Frequency at Which the Absorption Coefficient is the Maximum}

We measured the sound absorption coefficients of a fiber assembly belonging to the viscosity resistance type by assuming an air space behind it. In this case, the relation between frequency $f_{0}(c / s)$, at which the absorption coefficient in the absorption characteristic reached a maximum, and the distance $d(\mathrm{~cm})$ between the rigid wall and the center of the sample was. :[2]

$$
f_{0}=K d^{-1}
$$

where $K$ was a constant decided by the sample.

Eq. (2) can be used fully if the relation between $K$ and $a$ factor in the make-up of a glass wool board is established. With this in mind, we chose 9 specimens having an observed apparent density closest to the nominal apparent density, from among many specimens cut off from glass wool boards of various thicknesses made by A \& Co. Table 4 shows their observed apparent densities. The absorption characteristics of the specimens were obtained by varying distance $L$ between the front surface of a specimen and the rigid wall from $2.5 \mathrm{~cm}$ to 5.0 and $15.0 \mathrm{~cm}$.

Table 4 Observed Apparent Density $\mathrm{Da}\left(\mathrm{kg} / \mathrm{m}^{3}\right)$ of Specimens Whose Sound Absorption Characteristics Were Obtained by Varying Depth of Air Space

\begin{tabular}{ccccc}
\multicolumn{1}{l}{$\begin{array}{l}\text { Thickness } \\
(\mathrm{cm})\end{array}$} & 1.3 & 2.5 & 5.0 & $\begin{array}{l}\text { Mean } \\
\text { value }\end{array}$ \\
$\begin{array}{l}\text { Nominal } \\
\text { apparent } \\
\text { density }\left(\mathrm{kg} / \mathrm{m}^{3}\right)\end{array}$ & & & & \\
\hline 8 & 7.45 & 7.86 & 8.18 & 7.83 \\
12 & 12.0 & 11.8 & 12.2 & 12.0 \\
24 & 24.5 & 24.0 & 24.3 & 24.3 \\
\hline
\end{tabular}

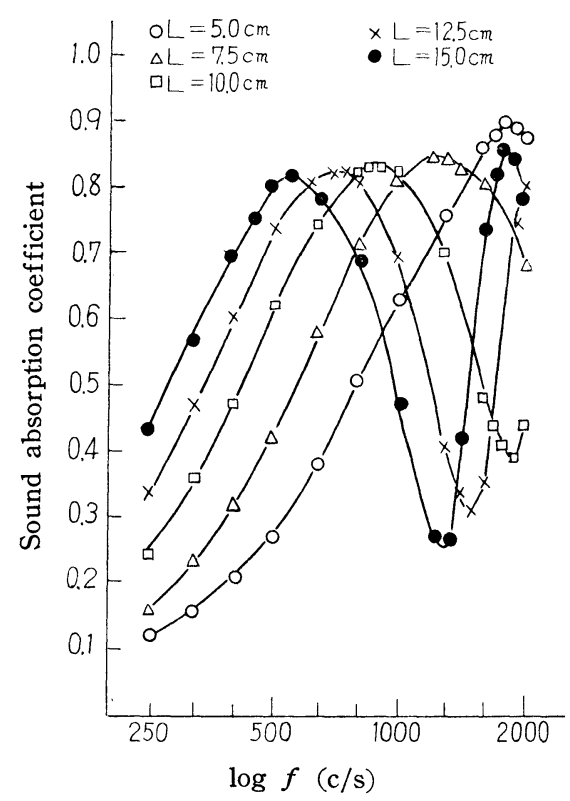

Fig. 5 Bearing which depth of air space has on sound absorption characteristics of specimen $11.8 \mathrm{~kg} / \mathrm{m}^{3}$ in observed apparent density ( $L$ is distance between front surface of specimen and rigid wall) 
One example is Fig. 5, giving the absorption characteristics of a specimen $2.5 \mathrm{~cm}$ in thickness and $11.8 \mathrm{~kg} / \mathrm{m}$ in apparent density. The maximum absorption coefficients in absorption characteristic at each $L$ were almost fixed. Accordingly, although we have discussed effective apparent density Dea under the condition $L=8.5 \mathrm{~cm}$, we may conclude that the value of Dea is unchanged, irrespective of the depth of the air space.

By substituting the observed $f_{0}$ and $d$ into eq. (2), we obtained $K$ of the values given in Table $5 . K$ for each sample is regarded as a constant. In other words, eq. (2) holds good for each sample. As for the specimen $T=5.0 \mathrm{~cm}$ and $D e=24.3 \mathrm{~kg} / \mathrm{m}$, it was difficult to $f_{0}$ because the curve in the neighborhood of the maximum absorption coefficient in the absorption characteristic was flat.

Table 5 Values of $K$ Obtained by Substituting into eq. (2) Frequency $f_{0}$ at Which a Specimen Gives the Maximum Sound Absorption Coefficient in an Absorption Characteristic and Distance $d$ between the Center of the Specimen and Rigid Wall

\begin{tabular}{|c|c|c|c|c|c|c|c|}
\hline \multirow{2}{*}{$\begin{array}{c}\text { Thickness } \\
T \\
(\mathrm{~cm}) \\
\end{array}$} & \multirow{2}{*}{$\underset{(\mathrm{cm})}{d}$} & \multicolumn{2}{|c|}{$8\left(\mathrm{~kg} / \mathrm{m}^{3}\right)$} & \multicolumn{2}{|c|}{$12\left(\mathrm{~kg} / \mathrm{m}^{3}\right)$} & \multicolumn{2}{|c|}{$24\left(\mathrm{~kg} / \mathrm{m}^{3}\right)$} \\
\hline & & $\begin{array}{c}f_{0} \\
(\mathrm{c} / \mathrm{s})\end{array} \mid$ & $K$ & $\begin{array}{c}f_{0} \\
(\mathrm{c} / \mathrm{s})\end{array}$ & $K$ & $\begin{array}{c}f_{0} \\
(\mathrm{c} / \mathrm{s})\end{array}$ & $K$ \\
\hline \multirow{5}{*}{1.3} & 4.35 & 2000 & 8700 & 1850 & 8050 & 1650 & 7180 \\
\hline & 6.85 & 1125 & 7710 & 1125 & 7710 & 1125 & 7710 \\
\hline & 9.35 & 900 & 8420 & 900 & 8420 & 825 & 7710 \\
\hline & 11.85 & 750 & 8890 & 700 & 8300 & 650 & 7700 \\
\hline & $\mid 14.35$ & 550 & 7890 & 500 & 7180 & 550 & 7890 \\
\hline \multicolumn{3}{|c|}{ Mean value } & 8320 & & 7930 & & 7640 \\
\hline \multirow{5}{*}{2.5} & 3.75 & 2000 & 7440 & 1800 & 6750 & 1650 & 6190 \\
\hline & 6.25 & 1300 & 8130 & 1200 & 7500 & 1150 & 7190 \\
\hline & 8.75 & 950 & 8310 & 875 & 7660 & 825 & 7220 \\
\hline & 11.25 & 750 & 8440 & 725 & 8160 & 620 & 6980 \\
\hline & 13.75 & 550 & 7560 & 550 & 7560 & 500 & 6880 \\
\hline \multicolumn{3}{|c|}{ Mean value } & 7980 & & 7530 & & 6890 \\
\hline \multirow{5}{*}{3.50} & 3.50 & 1800 & 6300 & 1600 & 5600 & & \\
\hline & 5.00 & 1325 & 6630 & 1150 & 5750 & & \\
\hline & 7.50 & 950 & 7130 & 850 & 6380 & & \\
\hline & 10.00 & 750 & 7500 & 700 & 7000 & & \\
\hline & 12.50 & 550 & 6880 & 525 & 6560 & & \\
\hline \multicolumn{3}{|c|}{ Mean value } & 6890 & & 6260 & & \\
\hline
\end{tabular}

If a standing wave which is $f_{0}(\mathrm{c} / \mathrm{s})$ in frequency is in a measuring tube empty of samples, and if the particle velocity of air is the maximum at distance $d$ $\mathrm{cm}$ from the rigid wall, then the relation between $f_{0}$ and $d$ is:

$$
f_{0}=c / 4 \cdot d^{-1}(c: \text { sound speed in air } \mathrm{cm} / \mathrm{sec})
$$

If a sample belonging to the viscosity resistance type is placed at a place where particle velocity is the maximum, the absorption coefficient is the maximum. However, since the sound speed in the sample belonging to the viscosity type slows down, $K<c / 4$. If a sample decreases in thickness to an infinitesimal, $K=c / 4=$ 8600. The relation between the mean value of $K$ for each sample and thickness $T$ is as shown in Fig. 6 and expressible by the following formula:

$$
K=c / 4-k T
$$

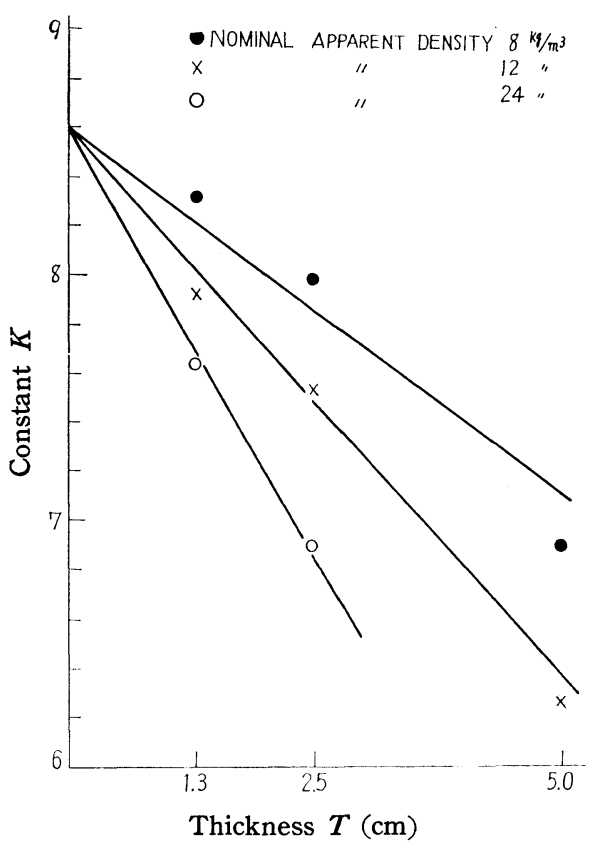

Fig. 6 Relation between thickness $T$ of samples made by $\mathrm{A} \&$ Co. and constant $K$ in eq. (2)

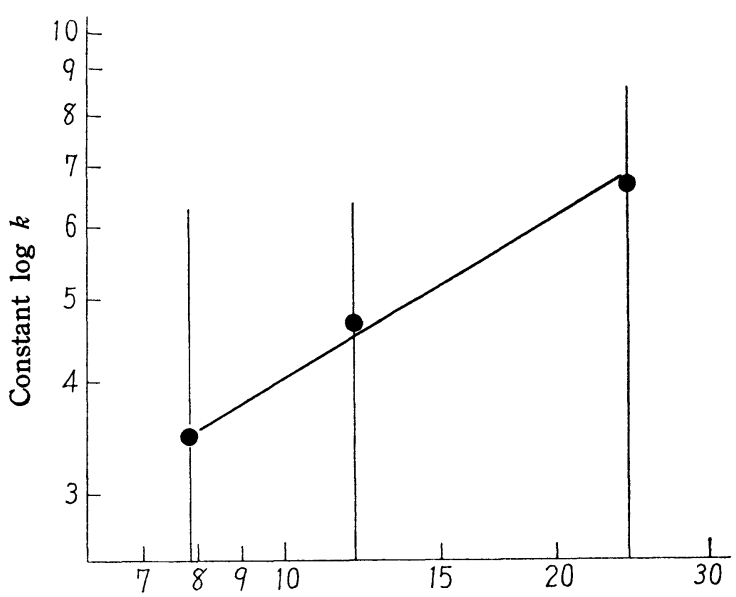

Observed apparent density $\log D_{a}\left(\mathrm{~kg} / \mathrm{m}^{3}\right)$

Fig. 7 Relation between observed apparent density $\mathrm{Da}$ of samples made by A \& Co. and constant $k$ in eq. (3) 
where $K$ is a constant decided by apparent density.

Since the observed apparent density $D a$ of specimens belonging to a certain nominal apparent density fluctuates as in Table 4, the values of $K$ in Fig. 6 deviate up and down from the lines of eq. (3), depend. ing on the values of $D a$.

The relation between $k$ computed by the method of least squares and the mean value of $D a$ by which $k$ is obtained makes a line on log-log section paper (see Fig. 7). Accordingly:

$$
k=\alpha D_{a^{\beta}}
$$

where $\alpha$ and $\beta$ are constants and where, for glass wool boards manufactured by A \& Co., $\alpha=100$ and $\beta$ $=0.606$. Substituting eqs. (3) and (4) into eq. (2) yields the following empirical formula :

$$
f_{0}=\left(c / 4-\alpha D_{a}^{\beta} \cdot T\right) d^{-1}
$$

If $d$ is so fixed as to make eq. (5) valid, a glass wool board absorbs a sound of certain frequency $f_{0}$ most. If a sample having an effective apparent density gives 1.00 in sound absorption coefficient at the frequency just mentioner.

\section{Conclusions}

In the light of the results of studies on the sound absorption characteristics of a fiber assembly, we have discussed the relation between sound absorption coefficient and apparent density of commercially sold glass wool boards. The results given in this article should be of interest to those making practical use of glass wool boards. It is to be hoped that a glass wool board having an apparent density which corresponds to effective apparent density will come on the market.

Absorption coefficients in our experiment were measured at Kobayashi Institute of Physical Research. The authors are deeply grateful to Mr. Masaru Koyasu of the institute for his suggestions, advice and supply of glass wool boards for the experiment.

\section{Reference}

[1] S. Aso and R. Kinoshita: J. Text. Mach. Soc. Japan; English edition, Vol. 10, No. 5, 209(1964)

[2] S. Aso and R. Kinoshita: J. Text. Mach. Soc. Japan: English edition, Vol. 11, No. 3, 81(1965)

[3] S. Aso and R. Kinoshita: J. Text Mach. Soc. Japan; English edition. Vol. 9 No. 1, 1(1963) 